\title{
How not to Argue from Science to Skepticism
}

\author{
Stephen Maitzen \\ Acadia University \\ smaitzen@acadiau.ca
}

\begin{abstract}
For at least several decades, and arguably since the time of Descartes, it has been fashionable to offer scientific or quasi-scientific arguments for skepticism about human knowledge. I critique five attempts to argue for skeptical conclusions from the findings of science and scientifically informed common sense.
\end{abstract}

\section{Keywords}

skepticism - knowledge - science - appearance - eliminativism - underdetermination - veil of perception

\section{1 \\ Introduction}

For at least several decades, and arguably since the time of Descartes, it has been fashionable to offer scientific or quasi-scientific arguments for skepticism about human knowledge. Indeed, when W. V. Quine describes this kind of skeptical program, he makes skepticism out to be as old as science itself, and science as old as common sense itself:

Scepticism is an offshoot of science. The basis for scepticism is the awareness of illusion, the discovery that we must not always believe our eyes.... The sceptic's example of the seemingly bent stick owes its force to our knowledge that sticks do not bend by immersion; and his examples of mirages, after-images, dreams, and the rest are similarly parasitic upon positive science, however primitive. ... [S]ceptical doubts are scientific doubts.

QUINE 1975: 67-8 
In what follows, I critique five attempts to argue for skeptical conclusions from the findings of science and common sense. ${ }^{1}$ In my view, all five attempts fail. Perhaps surprisingly, I won't discuss probably the best-known recent attempt to argue from science to skepticism: Alvin Plantinga's evolutionary argument against the rationality of believing naturalism and, by extension, against the knowledge that naturalism is true. Plantinga's argument has received ample and telling criticism to which I have nothing to add (see Beilby 2002).

Interestingly, Michael Levin has recently argued that no scientific or commonsense claims can be used to support skepticism aimed at science or common sense (Levin 2000). Levin's argument, however, depends on a pair of contentious premises:

(L1) Skeptical alternatives to common sense, such as the evil demon or brain-in-a-vat scenarios, must be metaphysically possible in order to threaten our knowledge.

(L2) Credibly claiming metaphysical possibility requires evidence not required for credibly claiming other kinds of possibility. ${ }^{2}$

In defense of L1, Levin argues that the mere logical possibility of a skeptical alternative, which he construes as the first-order logical consistency of the alternative, won't enable the alternative to threaten the certainty of any belief of ours that's otherwise certain. In order to do any work in the skeptic's argument, he says, a skeptical premise "must, however minutely, disconfirm any arbitrary" proposition $p$ that common sense accepts. But "no logical truth confirms, or disconfirms, anything," and so a premise asserting that the skeptical alternative is first-order consistent, an assertion that's a logical truth if it's true at all, can't disconfirm any commonsense proposition.

I don't find Levin's reasoning to this point convincing, assuming I understand it correctly, but I do think he's right to demand more from the skeptic than the mere logical possibility of the skeptical alternative, since logical possibility by itself needn't threaten knowledge: my own non-existence is logically possible in the sense of "first-order consistent" and in broader senses as well, but that fact in no way implies that I can't or don't know that I exist. Levin

1 For a detailed separate critique of skeptical arguments from dreaming and illusion, see Maitzen (2010).

2 "[E]stablishing [metaphysical] possibilities and impossibilities takes more than a self-certifying act of imagination or intuition. ... Strong possibility claims need a stronger backing; in a word, evidence" (Levin 2000: 426). 
rightly concludes that the mere logical possibility of a skeptical alternative doesn't bake any skeptical bread.

Levin also rightly notes that the skeptic can't without begging the question simply assume the epistemic possibility (for us) of the skeptical alternative, where epistemic possibility (for us) is consistency with everything we know. An alternative in which I'm a brain in a vat, for instance, isn't consistent with everything I know if indeed I know I have hands, and it's after all the skeptic's objective to show that I don't know I have hands, something the skeptical argument therefore can't simply presuppose (see Klein 1995). With epistemic possibility of that kind thus unavailable and logical possibility too weak for the job, Levin concludes that the skeptic has only metaphysical possibility left.

But the skeptic might instead invoke another sense of "epistemically possible" in which whatever isn't ruled out by our evidence is epistemically possible, the sense of "possible" invoked by the popular underdetermination argument for skepticism that I criticize below. According to the underdetermination argument, the brain-in-a-vat scenario, while admittedly ruled out by my knowledge that I have hands if I have such knowledge, is in any case not ruled out by the sensory evidence on which I base my belief that I have hands, for allegedly I would possess the very same evidence even if the scenario obtained. We have reason to distrust the underdetermination argument, as I explain below, but if the argument secures a non-question-begging kind of epistemic possibility for the skeptic's alternative, then it blocks Levin's argument for insisting on the alternative's metaphysical possibility.

Likewise, premise L2 seems odd because it demands that the skeptic provide evidence for the metaphysical possibility of the skeptical alternative. To illustrate what he means by "metaphysical possibility," Levin lists several things whose possibility in this sense he says philosophers continue to dispute, including backward causation. However, short of evidence for the actual existence of something, it's hard to see what evidence we could have for its metaphysical possibility that improves on the evidence we have for its logical or conceptual possibility. It's hard to see what could count as evidence for the metaphysical possibility of backward causation other than (evidence of) its conceptual coherence or else an actual case of it. Not even the consistency of backward causation with currently accepted physical laws would count as uncontroversial evidence in favor of its metaphysical possibility, since, for example, the proposition that water is other than $\mathrm{H}_{2} \mathrm{O}$ is consistent with physical laws accepted for centuries, but the proposition was no more (or less) metaphysically possible than it is today.

So it looks unreasonable to demand that the skeptic provide evidence of the metaphysical possibility of the skeptical alternative—-such as an actual case of 
an envatted and thoroughly deceived brain — that goes beyond the evidence for its logical or conceptual possibility. Moreover, even if the skeptic managed to establish the metaphysical possibility of a skeptical alternative, skepticism wouldn't follow any more readily than it does from the alternative's logical or conceptual possibility. Plenty of metaphysical possibilities are known not to obtain. My non-existence is metaphysically possible - there are infinitely many possible worlds in which I never exist - and yet the metaphysical possibility of my non-existence hardly threatens my actual knowledge that I exist, given that I exist and believe that I do. So L2's demand looks both unreasonable and irrelevant, and thus Levin's admittedly interesting attempt to block all arguments from science to skepticism looks unconvincing. We still have work to do.

\section{Two Fallacies}

2.1

\section{The Limits of Perspective}

I'll start with the easier targets and work my way toward the harder ones. Consider a potentially tempting argument for a skeptical conclusion from a commonsense or scientific premise about the limits of our perspective. One version goes as follows:

(A1) We perceive external objects only as we experience them.

(A2) Therefore, we don't perceive, and hence don't know, external objects as they are in themselves, i.e., independently of how we experience them; or

$\left(\mathrm{A}^{*}{ }^{*}\right)$ Therefore, we don't reliably perceive, and hence don't know, external objects as they are in themselves; or

$\left(\mathrm{A}^{* * *}\right)$ Therefore, it's only our good luck if we perceive objects as they are in themselves, and hence we don't know such objects as they are in themselves.

Read one way, A1 is a truism everyone ought to accept: we experience $x$ only as we experience $x$. But on that reading, A1 doesn't imply any of the versions of A2 drawn from it; a truism can't imply a substantive claim, including a substantive skeptical claim. Another reading of A1 emphasizes the word "only" in "only as we experience them" and thus smuggles in the presupposition that we never also experience external objects as they are in themselves; on this reading, all three versions of $\mathrm{A}_{2}$ follow from $\mathrm{A}_{1}$, but only because $\mathrm{A}_{1}$ begs the question in favor of skepticism right off. 
Nor does the argument improve by including an appeal to epistemic closure such as appears tacitly in premise B1 of this version:

(B1) If we know external objects as they are in themselves, then we know external objects as they are independently of our experience of them.

(B2) We don't know external objects as they are independently of our experience of them.

(B3) Therefore, we don't know external objects as they are in themselves.

For B2 suffers from the same ambiguity found in A1. The claim that we don't know external objects as they are "independently of our experience of them" might mean simply that our knowledge of external objects depends on our experience of them, but on that reading B2 doesn't imply B3. On the other and more obvious reading, $\mathrm{B}_{2}$ means that we don't know external objects as they are in themselves, but in that case the argument begs the question, since $\mathrm{B}_{2}$ becomes $\mathrm{B}_{3}$. Unless these arguments beg the question, then, none of their conclusions follow without adding questionable premises.

The fact that objects must reveal themselves to us through our experience of them doesn't imply that they don't also reveal themselves as they are independently of our experience of them. The fact that we perceive elephants as bigger than mice (and couldn't have that perception except via experience of both) doesn't imply that elephants aren't bigger than mice-in themselves, objectively, and regardless of our experience. In order to conclude that the limits of perspective rule out objective knowledge, we need some principle to the effect that elephants wouldn't be bigger than mice unless we perceived them that way - a principle we have no reason to accept.

$\mathbf{2 . 2}$

The Time-Lag Argument

A second skeptical argument, the "time-lag" argument, starts with the scientific fact that energy-transfer takes time and concludes that we're ignorant about the current existence or condition of external objects:

(C1) It takes time for energy (light, sound, etc.) to travel from a perceived object to its perceiver and for the perceiver's nervous system to process that energy into a sensory experience.

(C2) Therefore, no one ever experiences, at a time, an external object as it actually is at that time, and hence no one knows about the current existence or condition of an external object; or 
$\left(\mathrm{C}^{*}\right)$ Therefore, no one ever reliably experiences, at a time, an external object as it actually is at that time, and hence no one knows about the current existence or condition of an external object; or

$\left(\mathrm{C}{ }^{* *}\right)$ Therefore, it's only good luck if anyone ever perceives, at a time, an external object as it actually is at that time, and hence no one ever knows about the current existence or condition of an external object.

But the fact that we perceive an object as it was shortly ago doesn't imply that we don't also reliably perceive the object as it is now, for it may be now as it was then, and the law-governed behavior of objects and our senses can make such perception highly reliable. A scientific stickler might object, "Even if the way the object was shortly ago reliably indicates the way it is now, it's always too late to perceive the object as it is now, since energy travels at finite speed" (cf. Russell 1998: 16-7). Two replies. First, the stickler's objection relies on a narrow reading of the phrase "the way the object is now," but a broader reading is just as plausible: if, by way of an admittedly dated sense-impression, I perceive the apple as red, and the apple in fact still is red, then in that respect I perceive the apple as it is now. Second, even on the narrow reading the stickler's objection isn't scientific enough: to say that the apple is red at time $t$ just is to say that the apple would look red to a normal observer, not at $t$ but at some later time $t+n$, where $n$ is a function of the observer's distance; a scientifically informed description of many of an object's current features already assumes a time-lag. ${ }^{3}$

Again, one might try to bolster the skeptical argument with closure-based reasoning, as follows: "(i) If, on the basis of energy sent from $x$ some time ago, we know what $x$ is like now, then we know the following obvious logical consequence of that fact: $x$ hasn't changed in the meantime. (ii) We don't know that $x$ hasn't changed in the meantime. (iii) Therefore, we don't know what $x$ is like now." Step (ii) of that reasoning rests either on a counterfactual "sensitivity" analysis of knowledge or else on the idea that sensory data underdetermine our commonsense beliefs. I'll critique the underdetermination claim later on. According to the sensitivity analysis, we don't know that $x$ hasn't changed in the meantime because our current sensory experience would be the same now even if $x$ had changed in the meantime. However, as its proponents concede

3 Really scientific sticklers will insist on defining colors in terms of wavelengths of electromagnetic radiation rather than in phenomenal terms. To them I reply that the phenomenal definition is logically prior to the electromagnetic one, since without the phenomenal definition we don't know which range of wavelengths to associate with a particular color, i.e., which color we're trying to define electromagnetically. 
and even celebrate, the sensitivity analysis violates the closure principle, and so steps (i) and (ii) of the skeptic's reasoning rest on inconsistent foundations if (ii) rests on the sensitivity analysis of knowledge. In that case, we can't accept both premises, and the argument fails.

The time-lag argument can seem more compelling in the case of really big lags. Gazing at the Andromeda Galaxy through your backyard telescope, you may well wonder if the galaxy has ceased to exist in the more than two million years the light you're absorbing took to arrive: "Does it still exist, and does it look like that now?" The answer, however, is that your questions are illformed-meaningless-according to our best theory of spacetime. The problem isn't that any two simultaneous events lie outside each other's light-cones, for, again, without further assumptions that fact doesn't show that I can't know about events that are simultaneous with my knowing them. The problem is that the relativity of simultaneity implies that there's nothing it's like now in the Andromeda Galaxy — at any rate, nothing it's like now in any inertial reference-frame but the one occupied by the user of "now."4 If, therefore, skepticism seeks a truly scientific basis, it must face the prospect that the issue of what external objects are like now becomes less meaningful the more their distance from us prompts skeptical worries about our knowledge of them.

\section{$3 \quad$ Eliminativism}

In Scepticism Comes Alive, Bryan Frances defends "a new kind of radical scepticism" based, he emphasizes, not on cooked-up scenarios no one takes seriously but instead on skeptical alternatives that are "live" among scientists and philosophers (Frances 2005: vii). I'll concentrate on the first such alternative he discusses-eliminative materialism about the mind, or "eliminativism" for short-and use it to illustrate a weakness in one particular attempt to argue from science to skepticism. In the version of eliminativism that Frances invokes, no human being has propositional attitudes, and in particular no human being believes or accepts propositions (Frances 2005: 39). The motivation behind this view counts as scientific because the leading arguments for the view rely on the idea that mature cognitive science will have no place for the

4 Nevertheless, textbooks in philosophy sometimes give no hint that the issue may be ill-posed: "When we view the sky on a clear evening and think that we know at least something about how the star now looks, we are quite mistaken. The star might no longer exist at all, because what we see now is light that emanated from the star a number of years ago" (Cornman, Lehrer, \& Pappas 1992: 40). 
notions of propositional belief and acceptance or for anything similar to those notions.

Frances admits that, like most philosophers who have considered the issue, he rejects eliminativism so construed, but he takes pains to argue that eliminativism remains nonetheless a live possibility we haven't managed to rule out. Eliminativism, of course, implies our total lack of propositional knowledge, on the plausible assumption that propositional knowledge requires believing or accepting propositions. So, he says, it counts as an alternative that we can't eliminate and yet must eliminate in order to avoid skepticism.

I won't contest Frances's claim about the liveness of eliminativism, but I'll suggest that invoking eliminativism, or even just its liveness, is an unlikely route to skepticism. My objection rests on a principle,

(P1) No cogent argument for skepticism depends on invoking an alternative that's incompatible with skepticism, whose justification is a more general principle,

$(\mathrm{P} 2)$ If $p$ and $q$ are incompatible, then $q$ gains no support from our failure to rule out $p$.

If a given scenario would falsify skepticism were that scenario to obtain, then our inability to rule out the scenario can't threaten our knowledge in general. Take, for instance, the solipsistic alternative. Far from being a skeptical alternative, solipsism turns out to be incompatible with skepticism on a natural reading of skepticism. Barry Stroud, who takes himself to be echoing Kant on this point, makes a similar claim:

Of course if nothing at all existed in space, if everything that exists existed only in my own mind, Descartes's scepticism would lose its sting. It would be no limitation on my knowledge that I did not know of the existence of anything independent of me if there were nothing independent of me.

STROUD 1984: 129

Jonathan Dancy makes a stronger claim—or the same claim in stronger words-in the context of ethics:

In ethics there is, of course, the view that there are no moral facts to be known or believed at all. This is commonly called moral scepticism, but it should not be, for if there are no relevant facts there is nothing to be ignorant of.

DANCY 1992: 286

INTERNATIONAL JOURNAL FOR THE STUDY OF SKEPTICISM 4 (2014) 21-35 
On one reading of skepticism, solipsism does more than take the "sting" out of skepticism; it falsifies skepticism. Note that skeptics don't charge us with having only, or even mostly, false beliefs about the external world; they charge us with failing to know truths about the external world even if our external-world beliefs should happen to be true. But if solipsism is correct, then there's no external world for there to be truths about. In particular, "There is no external world" can't be a truth about the external world since there would be nothing for it to be about; it could be at most a truth about the concept external world, a truth asserting that nothing answers to the concept, just as "There are no ghosts" is a truth not about ghosts but about the concept ghost. On this view, then, if external-world skepticism implies that the truth about the external world entirely escapes our knowledge, solipsism and skepticism are incompatible: one precondition for skepticism is that there exist truths we fail to know. ${ }^{5}$

If the total absence of external-world truths would falsify skepticism, so too would the total absence of external-world beliefs. As Stroud puts it in a later work,

If all animate life were ... wiped off the face of the earth no one would then know anything or have any reason to believe anything about the world, but that would not make scepticism about the external world true. ... Scepticism holds that people as they actually are fail to know or have good reason to believe the sorts of things we all think we already know right now.

STROUD 1994: 291-2

I take Stroud's point to be that skepticism isn't, strictly speaking, the denial that human knowledge (of one kind or another) exists. More properly, skepticism is the denial that human knowledge exists because of the difference between true belief and knowledge: because the former doesn't automatically suffice for the latter. If no minds at all existed at the time of the Big Bang, then there was no knowledge back then, but it wouldn't follow that skepticism was true back then, because there were no true beliefs that could have fallen short of knowledge.

Therefore, according to P1 and contrary to Frances, eliminativism can't support skepticism. Granted, eliminativism has the consequence that none of our beliefs qualify as knowledge, since it implies that we have no beliefs, but by the

5 On this point, compare Quine: "In a world of immediate sense data with no bodies posited and no questions asked, a distinction between reality and illusion would have no place" (Quine 1975: 67). 
same token it has the consequence that all of our beliefs qualify as knowledge; if the first consequence counts in favor of skepticism, the second counts equally against it. Should the scales now seem balanced, we can break the tie by asking whether skepticism about human knowledge was true at the time of the Big Bang. Anti-skeptics who answer "yes" must conclude that skepticism went from being true to being false in the last few billion years, a conclusion that misunderstands skepticism. The proposition "No one knows anything" may have been true back then, but it has skeptical content only in a context in which subjects believe they have knowledge-or a context in which they at least believe something, because skepticism exploits the acknowledged gap between true belief and knowledge. These results reveal an important presupposition of my use of P1: skepticism doesn't claim merely that no human being knows anything; it claims that no human being knows anything even though some human beings think they do. The failure to rule out solipsism and eliminativism, even if it establishes that no one knows anything, doesn't thereby establish skepticism.

Admittedly I haven't argued for $\mathrm{P}_{1}$ except by invoking $\mathrm{P}_{2}$, and in case $\mathrm{P}_{1}$ seems questionable, I should note that a weaker conclusion that doesn't depend on P1 still holds. While solipsism and eliminativism are both incompatible with external-world knowledge, they're also (as I've argued) incompatible with skepticism, regardless of P1. Therefore, skeptics who think those two positions have skeptical force and can't be ruled out must concede that skepticism itself can't be known to be true-a concession more significant than it may sound, since skeptics often maintain that skepticism about the a posteriori can indeed be known a priori. By their own lights, however, it can't be known either way.

\section{Underdetermination}

The highly popular "underdetermination argument" for external-world skepticism borrows a theme from the philosophy of science about the empirical underdetermination of theories by data, and its deliberately scientific packaging makes it fair game for my critique of skeptical arguments from science. It strikes me as old wine in new bottles. The argument contends that our perceptual evidence doesn't confirm the hypothesis of commonsense realism over any well-designed skeptical alternative. As its proponents recognize, if the underdetermination argument deserves to be regarded as scientific, it must amount to more than the claim that purely subjective experience doesn't logically entail anything about the external world. For that claim is a truism 
guaranteed by the meaning of "purely subjective" as "not entailing anything about the external world." I'll argue, however, that the underdetermination argument is shaky if it does amount to more than a truism.

Unlike the relation of logical entailment, the confirmation relation is defeasible: while the conjunction $(p \& q)$ logically entails $r$ whenever $p$ entails $r$, the conjunction ( $p \& q)$ needn't confirm $r$ even if $p$ confirms $r$. Put another way, confirmation is a three-place relation among propositions (representing the evidence, the hypothesis, and the background assumptions), whereas entailment is merely a two-place relation between propositions. No evidence ever confirms a hypothesis except in the presence of contingent assumptions, and in particular assumptions that rule out defeaters. If I observe what looks like an electron-trail going across a cloud chamber, what I'm observing confirms the hypothesis that an electron passed by only if, or only to the degree to which, we assume the absence of anything else that would produce my observation: nobody scratched the glass of the chamber, or streaked the glass while cleaning it, or spoiled the photographic plate I'm examining, and so on without end. Almost all of these contingent assumptions are merely implicit in the "background knowledge" I bring to the observation, but the assumptions are in place all the same, or else I can't properly regard my observation as evidence.

If, therefore, we take seriously the analogy to science, the skeptical argument from underdetermination faces a dilemma. Either my current sensory experience confirms the commonsense hypothesis to some degree, or it doesn't. If my evidence does confirm common sense to some degree, then it does so only on background assumptions that rule out all skeptical alternatives; my sensation of having hands confirms the hypothesis that I have hands only if we assume, at least tacitly, that I'm not (say) a brain in a vat. If, on the other hand, my evidence doesn't confirm common sense to at least some degree, then the underdetermination argument reduces to old-fashioned infallibilism, i.e., the claim that my sensory evidence must logically entail the proposition I believe in order to justify my belief at all. ${ }^{6}$ If the underdetermination argument is infallibilism in disguise, then it's a priori, not scientific, and not new. It's either no help to the skeptic or else not an argument from science.

Again, an interesting argument from underdetermination must teach more than the lesson that evidence can confirm a hypothesis given one choice of assumptions while failing to confirm it given another choice. The defeasibility of confirmation teaches that lesson already and teaches it a priori. It can't, therefore, be news that my sensory evidence confirms common sense only relative to non-skeptical background assumptions and not relative to skeptical ones.

6 See also Brueckner (2005). I thank an anonymous referee for alerting me to this article. 
Defenders of the underdetermination argument like to say that commonsense ontology and a good skeptical hypothesis "both predict the same observations." But commonsense ontology predicts no observations at all on its own. The existence of medium-size material objects, animate and inanimate, accounts for my actual sensations only given contingent assumptions about my perceptual gear and about the absence of other sources of those sensations: in short, anti-skeptical assumptions. Sometimes, of course, our tacit background assumptions prove false. Physicists at the Swiss laboratory CERN tacitly assumed that their theory's predictions for the energy of particle-collisions needn't take account of the tides in Lake Geneva or the train schedule for the TGV that runs from Geneva to Paris. In fact, however, their theory predicts the actually observed values only after they factor in the geological effect of the tides and the electrical influence of the passing train (Randall 2005: 188). Underdetermination-skeptics say that common sense and a skeptical alternative are equally well-confirmed by the data. Unless by "equally well-confirmed" they mean "not confirmed at all in either case," the two contenders aren't equally well-confirmed relative to any stable set of background assumptions. If they do mean "not confirmed at all in either case," then the underdetermination argument is just infallibilism all over again.

\section{The Veil of Perception}

Skepticism based on the so-called "veil of perception," the last kind of skepticism I'll consider, claims support from the scientific idea that perception is an indirect causal process. Quine seems to allude to this kind of argument to underpin his famous suggestion that science may disprove the possibility of scientific knowledge via reductio ad absurdum. ${ }^{7}$ According to current science, any link in the causal chain of perception is sufficient (all else held constant) to produce all of the later ones, no matter how that link itself arose. Hence it's possible that the causal chain producing my perceptual experience involves mere nerve-stimulation in place of the objects I take myself to be perceiving, a result that makes scientific room for the skeptic's brain-in-a-vat scenario. I'll focus on the sense of "possible" invoked by this scientific argument for skepticism.

John McDowell and others have challenged what they see as a key inference in the traditional argument for veil-of-perception skepticism, an inference that the tradition apparently hasn't bothered to question. The inference starts with a premise I'll call the "Duplication Principle,"

7 See, e.g., Quine (1981: 22). I thank Richmond Campbell for the reference. 
(DP) For every veridical perceptual experience there's a possible introspectively indiscernible but deceptive experience, ${ }^{8}$

and ends with the assertion of what McDowell calls the "Highest Common Factor,"

(HCF) The subject is immediately aware of the same thing in both veridical and deceptive cases of experience. ${ }^{9}$

While McDowell and company are right to challenge the inference, I want to question the premise, DP itself. ${ }^{10}$ I want to question not so much the truth of $\mathrm{DP}$ as the claim that it gets any support from science.

One might try to support DP by starting with the empirical claim at the core of the skeptic's dream argument- "Each of us has actually undergone deceptive experiences introspectively indiscernible from veridical ones" - and generalizing from there to the epistemic possibility of deceptive duplicates for every veridical experience. But even if the induction is otherwise acceptable, the inference fails: we can't discover empirically, even in hindsight, that there are deceptive experiences introspectively indiscernible from non-deceptive ones unless we can know when we're not being thus deceived-unless, in other words, it's not epistemically possible that every experience is deceptive. ${ }^{11}$ To put it another way, empirical evidence for the claim "There are deceptive experiences" is itself evidence against the claim "For all we know, every experience is deceptive." Thus, if DP is to gain any support from science, the sense of "possible" in DP can't be epistemic.

If not epistemic possibility, then how about logical, metaphysical, or nomological? Logical possibility, when not inferred from actuality, is discovered $a$ priori rather than by empirical science. Not even the boldest skeptic claims that every experience actually is (relevantly) deceptive-a claim for which no one could have empirical evidence — so the logical possibility in DP isn't being inferred from actuality; in that case, the sense of possibility in DP is a priori, not empirical. The same goes for metaphysical possibility, as I explained in my critique of Levin: when not inferred from actuality it's discovered, if at all, $a$

\footnotetext{
8 Cf. Vinci (1986: 571$)$.

9 " $[\mathrm{T}]$ he argument is that since there can be deceptive cases experientially indistinguishable from non-deceptive cases, one's experiential intake - what one embraces within the scope of one's consciousness - must be the same in both kinds of case" (McDowell 1998: 386).

$10 \mathrm{~J}$. L. Austin expresses strong doubts about principles similar to DP in Austin (1962: 48-52).

11 For a defense of this claim, see Maitzen (2010).
} 
priori. ${ }^{12}$ So that leaves nomological, or "nomic," possibility: consistency with the currently accepted laws of nature. ${ }^{13}$ The phrase "currently accepted" matters in general but especially here, given the infancy of cognitive and perceptual neuroscience. These disciplines dare not claim to have discovered all the laws in their domains, or even all the laws that bear on the truth of DP, so let's not read too much into the consistency of universal perfect duplication with neuroscientific laws as currently accepted. Let's also remember that nomic possibility, even if fully established, has skeptical force only if it implies the relevant kind of epistemic possibility. My total non-existence is nomically possible but not epistemically possible, not for me at least: I can rule it out.

Perhaps inductive evidence for DP as a claim about nomic possibility could come from actual cases of duplication. But has neuroscience produced even a single case in which an illusory sense-impression genuinely duplicates a veridical one? If it has, how could we tell? Given the difficulty of scientifically capturing a subject's first-person perspective, and the varying levels of sensitivity and attentiveness among subjects, verifying a case of duplication looks daunting in the extreme. The familiar expression "Pinch me-I think I'm dreaming" implies the falsity of the Cartesian indiscernibility principle invoked by, among other things, the skeptic's dream argument: it implies that the sensation of being pinched can't be dreamt or otherwise faked. Do we know that it can be, and if so how do we know? Suppose that a near-enough duplication manages to produce in you the false belief that you're being pinched; is that episode grounds for inferring that any perceptual belief at all could be deceptively produced? Faced with such questions, defenders of DP may feel pressure to interpret it as claiming only logical or metaphysical possibility, in effect abandoning their empirical-scientific defense of skepticism and reverting to an old-fashioned a priori argument.

Quine says, in the passage I quoted at the start, "Scepticism is an offshoot of science." If he means that science shows us that we're fallible, then science shows us something we knew a priori, since, again, the claim that purely subjective experience isn't logically guaranteed to be veridical is a truism secured by the meaning of "purely subjective." If he means instead that science shows us that we actually make mistakes, the skeptic still owes us an argument from

12 This claim about our a priori knowledge of metaphysical possibility is compatible with, although independent of, the Putnam-Kripke claim that some metaphysical necessities (e.g., "Water is $\mathrm{H}_{2} \mathrm{O}$ ") are knowable only a posteriori.

13 Nomological possibility is already murky territory. Is it nomologically possible for a human being to high-jump 50 feet in normal gravity? That may depend on how big someone can get while still belonging to our species. 
the known fact that we make mistakes to the skeptical claim that we could always be mistaken, in the epistemic sense of "could." I have tried to show how elusive such an argument will be. ${ }^{14}$

\section{References}

Austin, J. L. (1962). Sense and Sensibilia. London: Oxford University Press.

Beilby, J. (ed.). (2002). Naturalism Defeated?: Essays on Plantinga's Evolutionary Argument Against Naturalism. Ithaca and London: Cornell University Press.

Brueckner, A. (2005). "Fallibilism, Underdetermination, and Skepticism," Philosophy and Phenomenological Research 7:384-391.

Cornman, J. W., Lehrer, K. \& Pappas, G. S. (1992). Philosophical Problems and Arguments: An Introduction. Indianapolis, IN: Hackett Publishing.

Dancy, J. (1992). "Moral Epistemology," 286-9o in J. Dancy \& E. Sosa (eds.), A Companion to Epistemology. Oxford: Blackwell.

Frances, B. (2005). Scepticism Comes Alive. Oxford: Clarendon Press.

Klein, P. (1995). "Skepticism and Closure: Why the Evil Genius Argument Fails," Philosophical Topics 22: 213-36.

Levin, M. (2000). "Demons, Possibility and Evidence," Noûs 34: 422-40.

Maitzen, S. (2010). "A Dilemma for Skeptics," Teorema 29: 23-34.

McDowell, J. (1998). Meaning, Knowledge, and Reality. Cambridge, MA, \& London: Harvard University Press.

Quine, W. V. (1975). "The Nature of Natural Knowledge," $67-81$ in S. Guttenplan (ed.), Mind and Language. Oxford: Clarendon Press.

—. (1981). Theories and Things. Cambridge, MA: Harvard University Press.

Randall, L. (2005). Warped Passages. New York: Harper Collins.

Russell, B. (1998). The Problems of Philosophy. 2nd edition. Oxford \& New York: Oxford University Press.

Stroud, B. (1984). The Significance of Philosophical Scepticism. Oxford: Clarendon Press. - (1994). "Skepticism, 'Externalism', and the Goal of Epistemology," Proceedings of the Aristotelian Society, Supp. Vol. 68: 291-307.

Vinci, T. (1986). "Critical Notice of Barry Stroud: The Significance of Philosophical Scepticism," Canadian Journal of Philosophy 16: 559-74.

14 For helpful comments on an earlier version of this paper, I thank Andrew Graham; audiences at Dalhousie University, the University of Edinburgh, and the University of Glasgow; and an anonymous referee for this journal. 